\title{
Testcross Performance of Three Selection Cycles from Four Pickling Cucumber Populations
}

\author{
Christopher S. Cramer ${ }^{1}$ and Todd C. Wehner \\ Department of Horticultural Science, Box 7609, North Carolina State University, Raleigh, NC, 27695-7609
}

\begin{abstract}
AdDitional IndeX words. Cucumis sativus, Cucurbitaceae, earliness, fruit shape, recurrent selection, yield
Abstract. Progress was measured in four populations of cucumber (Cucumis sativus L.) improved by recurrent selection. The populations were the North Carolina wide base pickle (NCWBP), medium base pickle (NCMBP), elite pickle 1 (NCEP1), and hardwickii 1 (NCH1). Families from each of three cycles (early, intermediate, and late) from each population were randomly chosen and crossed with Gy 14 to produce gynoecious hybrids. Gy 14 is a gynoecious inbred used commonly as a female parent in the production of pickling cucumber hybrids. Once the plants had $10 \%$ oversized (>51 $\mathrm{mm}$ in diameter) fruit, plots were sprayed with paraquat to simulate once-over harvest. Selection cycles were evaluated for total, early, and marketable yield, and fruit shape. Testcross performance for fruit shape rating increased over cycles for the NCWBP and NCMBP populations when tested in either season. Testcross performance for total and early yield of the NCEP1 population tested in the spring decreased with selection, but remained constant over cycles in the summer season. The majority of yield traits in each population remained unchanged across selection cycles. Of the four populations studied, the NCMBP population had the greatest gain $(7 \%)$ in testcross performance over cycles and averaged over all traits. In addition, testcross performance for fruit shape rating had the greatest gain (11\%) with selection and averaged over populations. Years and seasons greatly influenced testcross performance for fruit yield and shape rating. In most instances, the fruit yield and shape of Gy 14 was higher than the testcross performance of population-cycle combinations. The performance of several families exceeded that of $\mathrm{Gy} 14$ when testcross combinations were made. Those families could be selected for use in the development of elite cultivars. Chemical name used: 1,1'dimethyl-4,4'-bipyridinium ion (paraquat).
\end{abstract}

North Carolina is the second leading state in the production of pickling cucumber (Cucumis sativus) in the United States, and cucumber is the second most important vegetable crop in North Carolina (U.S. Dept. Agr., 1998). Since 1900, increased yield has been one of the important objectives in cucumber breeding programs (Wehner, 1989). Increased yield of cucumber cultivars has resulted from improvement of qualitative traits, such as gynoecious expression and disease resistance. Progress per se for yield, earliness, and fruit shape has been more difficult to achieve because those traits are inherited quantitatively and have low heritability.

Recurrent selection has been used to improve quantitative traits that have low heritability through cumulative gains obtained from successive cycles of selection. Recurrent selection methods, such as $\mathrm{S}_{1}$ line, half-sib, and full-sib family selection, have been effective for yield improvement in cucumber (Lertrat and Lower, 1983, 1984; Nienhuis and Lower, 1988; Wehner, 1989; Wehner and Cramer, 1996a, 1996b). Using modified half-sib family recurrent selection, Wehner and Cramer (1996a) observed an average of 54\% gain in yield for the North Carolina medium based pickling cucumber (NCMBP) population intercrossed for 10 cycles. In addition, early yield increased $65 \%$ on average for three pickling cucumber populations intercrossed for 10 cycles of selection.

While we have demonstrated progress per se from recurrent selection in pickling cucumber populations, we were interested in

Received for publication 11 Mar. 1998. Accepted for publication 10 Feb. 1999. This research was funded in part by the North Carolina Agricultural Research Service (NCARS), Raleigh, NC 27695-7643. Use of trade names in this publication does not imply endorsement by the NCARS of the products named, nor criticism of similar ones not mentioned. We gratefully acknowledge technical assistance of Tammy L. Ellington, Rufus R. Horton, Jr., Jinsheng Liu, Nischit V. Shetty, Joel L. Shuman, and S. Alan Walters. The cost of publishing this paper was defrayed in part by the payment of page charges. Under postal regulations, this paper therefore must be hereby marked advertisement solely to indicate this fact.

${ }^{1}$ Current address: Department of Agronomy and Horticulture, Box 30003, Dept. 3Q, New Mexico State University, Las Cruces, NM 88003-8003. measuring the progress made for testcross performance with an elite inbred line. Testcross performance for yield has been used in pickling cucumber to measure progress using different breeding strategies (Lertrat and Lower, 1983, 1984; Nienhuis and Lower, 1988). Therefore, the objectives of this study were to 1) determine the performance of random $S_{1}$ families from four pickling cucumber populations hybridized to a common tester, and 2) measure the progress made over selection cycles.

\section{Materials and Methods}

Population formation AND SELECTION. Four pickling cucumber populations were developed at North Carolina State University. The North Carolina wide base pickle (NCWBP) population was formed by intercrossing 1165 cultigens (cultivars, breeding lines, and other accessions) and selecting for pickle types (Wehner, 1997). Sixty-nine of the best pickling cultigens were intercrossed to form the North Carolina medium base pickle (NCMBP) population (Wehner, 1997). The North Carolina elite pickle 1 (NCEP1) population consisted of eight elite pickling cultigens intercrossed in 1981 and 1982, and the North Carolina hardwickii 1 (NCH1) population consisted of 12 cultigens crossed with LJ 90430 (Cucumis sativus var. hardwickii) and then intercrossed randomly from 1976 to 1982 (Wehner, 1997; 1998). Populations differed in their genetic diversity $(\mathrm{NCWBP}=$ highest, NCEP1 = lowest $)$ and mean yield performance $(\mathrm{NCEP} 1=$ highest, $\mathrm{NCWBP}=$ lowest $)$ (Wehner, 1997; 1998). The populations were improved using modified intra-population half-sib family recurrent selection for fruit yield, earliness, and shape of the population. The methods have been described previously (Wehner and Cramer, 1996a). Half-sib families were selected in the spring based on a simple weighted index, which was weighted $20 \%$ total yield, $20 \%$ marketable yield, 30\% early yield, and 30\% fruit quality (Wehner and Cramer, 1996a). Populations were also selected for general adaptation to North Carolina growing conditions in the spring and summer seasons (Wehner, 1997, 1998). 
Progress evaluation. The recurrent selection cycles chosen from each population were cycles $0,3,5$ for NCWBP, cycles 0,5 , 10 for NCMBP and NCH1, and cycles 0, 5, 9 for NCEP1. In all cases, we used the earliest and latest selection cycles available along with an intermediate selection cycle. In 1995, seven $S_{1}$ and four $S_{0}$ families were randomly selected from each of the three selected cycles in each population and hybridized individually to the female parent, Gy 14, a gynoecious pickling inbred used as the female parent in many pickling cucumber hybrids. $S_{0}$ families were used because not enough $S_{1}$ families were generated in time to conduct the designed experiment in 1995. Differences in testcross performance between $S_{0}$ and $S_{1}$ families were not observed (Cramer, 1997 unpublished results). In 1996, $11 \mathrm{~S}_{1}$ families were randomly selected from each population-cycle combination and then were hybridized individually with Gy 14 . In each year, the 11 randomly selected families from each populationcycle combination represented the genetic variation for that cycle of selection.

The experiment was a split-plot treatment arrangement in a randomized complete-block design with 22 replications per cycle (two replications per family) in each of two seasons (spring and summer) in each of 2 years (1995 and 1996). In North Carolina trials, seasons provide more information than locations, and are just as effective as years (Swallow and Wehner, 1989). Whole plots were the four pickling populations, and subplots were the three cycles of recurrent selection (early, intermediate, late) along with the checks [Gy 14 (gynoecious inbred) and 'Sumter' (monoecious inbred)].

Twenty-three seeds were planted in 1.2-m-long plots on raised, shaped beds on 17 May 1995 and 29 Apr. 1996 for the spring season, and on 13 July 1995 and 8 July 1996 for the summer season at the Horticultural Crops Research Station, Clinton, N.C. In addition, guard rows and 1.2-m-long end plots were used to provide competition for plants in the outside plots (Wehner, 1989). The plot size for this study was chosen based on recommendations by Swallow and Wehner (1986) for the optimum plot size for once-over harvest of pickling cucumbers using paraquat. Small, single-row plots were used because they were more efficient than large, multiple-row plots (Wehner and Miller, 1990).

Plots were thinned to 16 plants (10 in Spring 1995, due to cold, wet weather). The test plots were harvested 10 July 1995 and 27 June 1996 for the spring season, and harvested 8 Sept. 1995 and 26 Aug. 1996 for the summer season. Once-over harvest was simulated by spraying the foliage with paraquat at $0.6 \mathrm{~kg} \cdot \mathrm{ha}^{-1}$ when the plots had reached the $10 \%$ oversized $(>51 \mathrm{~mm}$ in diameter) fruit stage (Wehner et al., 1984). The soil type was a mixture (through the fields used) of Norfolk, Orangeburg, and Rains (fine-loamy, siliceous, thermic, Typic Kandiudults) with some Goldsboro (fine-loamy, siliceous, thermic, Aquic Paleudults). Recommended cultural practices were used throughout the experiment (Schultheis, 1990).

Testcross families were evaluated for total yield (number of fruit per plot), early yield (number of oversized fruit per plot), percentage marketable yield (total yield minus crooked- and nubbin-shaped fruit divided by total), fruit shape rating (Strefeler and Wehner, 1986), and a simple weighted index (SWI) (Wehner, 1982). Fruit shape rating reflected how straight, uniform, and cylindrical the fruit in a plot were, and was based on a scale of 19, where $1-3=$ poor, $4-6=$ intermediate, $7-9=$ excellent $($ Strefeler and Wehner, 1986). The simple weighted index was calculated as: SWI $=0.2($ total yield $/ 2)+0.3$ (early yield $)+0.2$ (percentage marketable yield/10) + 0.3 (fruit shape rating) (Wehner, 1982)

Data analysis. Plots from 1996 and Summer 1995 were corrected to 16 plants per plot for plots with 8 to 15 plants (plots with fewer than eight plants were considered missing). Plots from Spring 1995 were corrected to 10 plants per plot for plots with five to nine plants (plots with fewer than five plants were considered missing). Fruit yield and shape were corrected by dividing by plant stand and multiplying by 10 or 16 depending on the season. Plots with low stands were eliminated from the analysis to prevent extreme biasing from stand correction. Plant stands were corrected to reduce mean differences in fruit yield and shape resulting from differences in stand (Cramer and Wehner, 1998b). The stand correction increased coefficient of determination values and decreased coefficient of variability values for most analyses (data not shown). Differences in trait means over years, over seasons, over cycles, and over populations were determined using analysis of variance from SAS (SAS Institute Inc., Cary, N.C.). The model used assumed seasons and years as random effects and populations and cycles as fixed effects. Trait means for populations and for cycles were separated using a protected Fisher's least significant difference (LSD) mean separation test at $P=0.05$. Data were sorted by population and then by season. A linear response of fruit yield and quality to selection cycles was determined using analysis of variance and orthogonal contrasts for cycles linear. Separate orthogonal coefficients were used for each population depending on the spacing between selection cycles. Checks were excluded from the statistical analysis, but were included with cycle means for comparisons of progress made.

\section{Results and Discussion}

When averaged across years, seasons, replications, and cycles, populations were similar in testcross performance for fruit yield and SWI (Table 1). Of the four populations tested, the NCEP1 and $\mathrm{NCH} 1$ populations had the highest testcross performance for fruit shape rating. Fruit shape rating averaged over all populations increased $11 \%$ from early to late selection cycles (Table 1 ). Conversely, testcross performance for total fruit yield decreased $4 \%$ from early to late selection cycles. Since the intermediate and late selection cycles chosen from each population were different, comparisons between populations for a particular cycle should be made with caution. However, our choice of certain selection cycles was more to select different stages of population development using recurrent selection rather than compare exact selection cycles between populations. Therefore, comparisons between early, intermediate, and late selection cycles averaged over all populations are useful.

With regard to the check cultivars, the total and early yield, and SWI of Gy 14 exceeded testcross performance for yield of each population and selection cycle (Table 1). Each population and cycle had a higher percentage marketable yield than Gy 14 . In addition, testcross performance for fruit shape rating of the NCEP1 and NCH1 populations, and the intermediate and late selection cycles was higher than the fruit shape rating of Gy 14 . Even though few population-cycle means exceeded Gy 14 for fruit yield and shape rating, the two highest families (based on SWI) were selected from each population-year-cycle combination (data not shown). Of the 48 families selected, only one family exceeded Gy 14 for total yield, early yield, and SWI, while eight families exceeded Gy 14 for either percentage marketable fruit or fruit shape rating. The majority of families were comparable to Gy 14 for fruit yield and shape rating.

Fruit yield and shape rating was influenced greatly by environment, as evidenced by large differences in testcross performance for fruit yield and shape between seasons and between years 
Table 1. Mean values ${ }^{\mathrm{z}}$ of number of total and early fruit per plot, percentage of marketable fruit, fruit shape rating, and simple weighted index (SWI $\left.{ }^{\mathrm{y}}\right)$ for testcross performance of families crossed with Gy 14 .

\begin{tabular}{|c|c|c|c|c|c|}
\hline Effect & $\begin{array}{l}\text { Total } \\
\text { (no.) }\end{array}$ & $\begin{array}{l}\text { Early } \\
\text { (no.) }\end{array}$ & $\begin{array}{c}\text { Marketable } \\
(\%)\end{array}$ & $\begin{array}{l}\text { Shape } \\
\text { rating }\end{array}$ & SWI \\
\hline$\overline{\text { Grand }}$ & 20.4 & 8.7 & 87.9 & 6.2 & 8.3 \\
\hline \multicolumn{6}{|l|}{ Year } \\
\hline 1995 & 16.1 & 9.9 & 88.0 & 5.9 & 8.1 \\
\hline 1996 & 24.3 & 7.6 & 87.7 & 6.5 & 8.4 \\
\hline F ratio & $554.7^{* * * *}$ & $36.1^{* * * *}$ & 0.8 & $45.2^{* * * * *}$ & $5.3^{*}$ \\
\hline \multicolumn{6}{|l|}{ Season } \\
\hline Spring & 18.2 & 8.0 & 85.8 & 6.4 & 7.9 \\
\hline Summer & 22.6 & 9.3 & 89.9 & 6.0 & 8.7 \\
\hline F ratio & $152.9^{* * * *}$ & $17.4^{* * * *}$ & $\mathbf{5 5 . 0} \mathbf{0}^{* * * *}$ & $27.9^{* * * *}$ & $37.1^{* * * *}$ \\
\hline \multicolumn{6}{|l|}{ Population } \\
\hline NCWBP & 20.3 & 8.4 & 87.4 & 5.9 & 8.1 \\
\hline NCMBP & 20.9 & 8.6 & 88.4 & 6.1 & 8.3 \\
\hline NCEP1 & 20.3 & 8.9 & 87.7 & 6.4 & 8.4 \\
\hline $\mathrm{NCH} 1$ & 20.2 & 8.8 & 88.0 & 6.4 & 8.3 \\
\hline $\operatorname{LSD}_{(0.05)}$ & 0.9 & 0.8 & 1.5 & $0.2^{* * * *}$ & 0.3 \\
\hline \multicolumn{6}{|l|}{ Cycle } \\
\hline Early & 21.2 & 8.6 & 87.8 & 5.8 & 8.2 \\
\hline Intermediate & 19.9 & 8.6 & 88.2 & 6.4 & 8.3 \\
\hline Late & 20.2 & 8.8 & 87.5 & 6.4 & 8.3 \\
\hline $\operatorname{LSD}_{(0.05)}$ & $0.8^{* * *}$ & 0.7 & 1.3 & $0.2^{\text {***** }}$ & 0.3 \\
\hline \multicolumn{6}{|l|}{ Check } \\
\hline Gy 14 & 24.4 & 10.2 & 86.0 & 5.9 & 9.0 \\
\hline Sumter & 12.3 & 4.0 & 85.9 & 6.5 & 6.2 \\
\hline
\end{tabular}

${ }^{\mathrm{z}}$ Data are means of 1056 (grand), 528 (year, season), 352 (cycle), 264 (population), or 176 (check) replications of 16 plants per plot. ${ }^{\mathrm{y} S W I}=0.2($ total $/ 2)+0.3($ early $)+0.2(\%$ marketable $/ 10)+0.3$ (shape $)$.

$*^{* * *, * * *}$ Indicates mean square for years, seasons, populations, and cycles significant at $P=0.05,0.01$ or 0.001 , respectively.

(Table 1). The environmental differences in yield were larger than genetic differences in yield among populations and among selection cycles. Large amounts of environmental variation for yield make progress for yield difficult to achieve. In previous research, the narrow-sense heritability of yield for several cucumber populations was 0.17 to 0.25 (Smith et al., 1978; Strefeler and Wehner, 1986). In addition, heritability for fruit shape rating has been reported to be 0.00 to 0.30 using full-sib family recurrent selection (Strefeler and Wehner, 1986). Lertrat and Lower $(1983,1984)$ observed a decrease of 0.5 fruit per plant from 1982 to 1983 for two populations crossed with Gy 14 as a tester. In addition, Wehner (1984) conducted a uniformity trial with 'Calypso' and found fruit yield to range from 9 to 35 fruit per $1.5-\mathrm{m}$-long plot in a single test. Thus, fruit yield and shape rating in pickling cucumber has been highly variable within and between environments, and has low heritability.

Since there were seasonal differences for each trait, and since populations were primarily selected in the spring season, means were calculated separately for each population and cycle for the spring and summer seasons (Table 2). For the NCMBP population, testcross performance for total yield in the summer season decreased linearly from cycle 0 to cycle 10 but remained unchanged from cycle 0 to cycle 10 in the spring season (Table 2). Testcross performance for total and early yield and SWI of the NCEP1 population decreased from cycle 0 to cycle 9 when tested in the spring season but remained constant in the summer season (Table 2). Testcross performance for total and early yield of the NCWBP and NCH1 populations, and for early yield and SWI of the NCMBP population remained constant with selection in both seasons (Table 2). Several slicing cucumber populations exhibited similar responses in testcross performance for fruit yield and shape rating over cycles of selection (Cramer and Wehner, 1998a).

Since recurrent selection for improved fruit yield per se was conducted in the spring season, progress would be expected when populations were tested only in that environment. However in several instances, progress for testcross performance for fruit shape rating was also observed in the nonselected environment (summer season). Testcross performance for fruit shape rating increased linearly from early to late selection cycles for the NCWBP and NCMBP populations tested in either season (Table 2). For the NCH1 population, testcross performance for fruit shape decreased in the spring season and increased linearly in the summer season from cycle 0 to cycle 10 . Wehner and Cramer (1996a) also observed progress for fruit shape rating when populations were tested in a nonselected environment.

In some cases, gains made in testcross performance for fruit yield and shape rating paralleled gains made in the populations per se (Wehner and Cramer, 1996a). For example, the gain in testcross performance for fruit shape rating of the NCWBP and NCMBP populations in both seasons was similar to the gain in fruit shape rating for each population in both seasons. In addition, there was no gain for either testcross performance for fruit shape rating or for fruit shape rating of the NCEP1 population when tested in either environment (Wehner and Cramer, 1996a). When the $\mathrm{NCH} 1$ population was tested in the nonselected environment, both testcross performance for fruit shape rating and fruit shape increased linearly over selection cycles (Wehner and Cramer, 1996a). Lack of response in testcross performance for total and early yield in the NCWBP population could be explained by lack of response for both traits (unpublished data). A similar lack of response in testcross performance for total and early yield paralleled that of total and early yield in the $\mathrm{NCH} 1$ population when 
Table 2. Mean values ${ }^{\mathrm{z}}$ and $\mathrm{F}$ ratios (cycles linear) of testcross performance for total and early fruit per plot, fruit shape rating, and simple weighted index $\left(\mathrm{SWI}^{\mathrm{y}}\right)$ of families crossed with Gy 14 (along with Gy 14 check) in each population, cycle and season.

\begin{tabular}{|c|c|c|c|c|c|}
\hline Season & Cycle & $\begin{array}{l}\text { Total } \\
\text { (no.) }\end{array}$ & $\begin{array}{l}\text { Early } \\
\text { (no.) }\end{array}$ & $\begin{array}{l}\text { Shape } \\
\text { rating }\end{array}$ & SWI \\
\hline \multicolumn{6}{|l|}{$\overline{\mathrm{NCWBP}}$} \\
\hline \multirow[t]{5}{*}{ Spring } & 0 & 18.0 & 7.2 & 5.3 & 7.3 \\
\hline & 3 & 18.1 & 6.3 & 6.6 & 7.4 \\
\hline & 5 & 17.9 & 7.9 & 6.7 & 7.8 \\
\hline & F ratio & 0.0 & 0.3 & $34.8^{\text {**** }}$ & 1.9 \\
\hline & Gy 14 & 20.6 & 8.3 & 6.4 & 8.1 \\
\hline \multirow[t]{5}{*}{ Summer } & 0 & 23.6 & 10.1 & 5.1 & 8.7 \\
\hline & 3 & 20.8 & 8.9 & 6.1 & 8.4 \\
\hline & 5 & 23.0 & 9.7 & 5.9 & 8.8 \\
\hline & F ratio & 0.5 & 0.2 & $17.3^{* * * *}$ & 0.0 \\
\hline & Gy 14 & 28.8 & 12.9 & 5.9 & 10.3 \\
\hline \multicolumn{6}{|l|}{ NCMBP } \\
\hline \multirow[t]{5}{*}{ Spring } & 0 & 19.2 & 7.1 & 5.5 & 7.4 \\
\hline & 5 & 18.1 & 8.1 & 6.8 & 8.0 \\
\hline & 10 & 18.2 & 8.3 & 6.4 & 8.0 \\
\hline & $F$ ratio & 2.3 & 0.7 & $13.7^{* * * *}$ & 0.9 \\
\hline & Gy 14 & 24.1 & 11.3 & 6.0 & 9.3 \\
\hline \multirow[t]{5}{*}{ Summer } & 0 & 25.2 & 9.1 & 5.4 & 8.6 \\
\hline & 5 & 22.5 & 10.0 & 6.5 & 9.1 \\
\hline & 10 & 21.2 & 9.0 & 6.3 & 8.5 \\
\hline & $F$ ratio & $5.5^{*}$ & 1.2 & $20.3^{* *}$ & 1.5 \\
\hline & Gy 14 & 24.6 & 9.3 & 6.0 & 8.8 \\
\hline \multicolumn{6}{|l|}{ NCEP1 } \\
\hline \multirow[t]{5}{*}{ Spring } & 0 & 19.4 & 9.3 & 6.5 & 8.4 \\
\hline & 5 & 17.4 & 8.5 & 6.7 & 8.0 \\
\hline & 9 & 16.5 & 6.6 & 6.6 & 7.4 \\
\hline & F ratio & $7.0^{*}$ & 4.1 $1^{*}$ & 0.1 & $4.3^{*}$ \\
\hline & Gy 14 & 21.6 & 9.8 & 5.7 & 8.5 \\
\hline \multirow[t]{5}{*}{ Summer } & 0 & 24.4 & 9.8 & 6.2 & 9.0 \\
\hline & 5 & 22.3 & 9.6 & 6.2 & 8.8 \\
\hline & 9 & 22.3 & 9.4 & 6.4 & 8.8 \\
\hline & F ratio & 2.2 & 0.8 & 0.9 & 0.2 \\
\hline & Gy 14 & 26.9 & 10.3 & 5.7 & 9.4 \\
\hline \multicolumn{6}{|l|}{$\mathrm{NCH} 1$} \\
\hline \multirow[t]{5}{*}{ Spring } & 0 & 18.3 & 8.3 & 6.9 & 8.1 \\
\hline & 5 & 18.9 & 9.5 & 6.7 & 8.5 \\
\hline & 10 & 18.7 & 9.0 & 6.4 & 8.2 \\
\hline & F ratio & 0.2 & 0.9 & $4.6^{*}$ & 0.2 \\
\hline & Gy 14 & 18.8 & 9.1 & 6.0 & 8.1 \\
\hline \multirow[t]{5}{*}{ Summer } & 0 & 21.1 & 8.1 & 5.9 & 8.1 \\
\hline & 5 & 22.8 & 8.9 & 6.1 & 8.6 \\
\hline & 10 & 21.5 & 9.0 & 6.3 & 8.6 \\
\hline & $F$ ratio & 0.7 & 0.5 & $5.0^{*}$ & 1.6 \\
\hline & Gy 14 & 28.0 & 10.0 & 5.5 & 9.2 \\
\hline
\end{tabular}

${ }^{\mathrm{z}}$ Data are means of 44 (population-cycle) or 22 (Gy 14) replications of 16 plants in each season.

${ }^{\mathrm{y} S W I}=0.2($ total $/ 2)+0.3($ early $)+0.2(\%$ marketable $/ 10)+0.3($ shape $)$.

$*, * *, * * *$ Indicates mean square for cycles linear significant at $P=0.05,0.01$, or 0.001 , respectively.

tested in the selected environment (Wehner and Cramer, 1996a). Thus, much of the progress or lack of progress in testcross performance for fruit yield and shape paralleled that for fruit yield and shape.

Of the four populations, the NCMBP population exhibited the greatest gain $(7 \%)$ in testcross performance from cycle 0 to cycle 10 averaged across all four traits while the NCH1 and NCWBP populations averaged $3 \%$ to $5 \%$ gain from early to late cycles averaged over all traits. Conversely, the NCEP1 population decreased by $7 \%$ from cycle 0 to cycle 9 averaged across all four traits. The responses of testcross performance for fruit yield and shape rating were similar to the responses of fruit yield and shape rating when averaged over traits or populations. Of the four populations studied, the NCMBP population also had the largest gain in fruit yield and shape rating when averaged over all four traits (Wehner and Cramer, 1996a). When averaged over populations, testcross performance for fruit shape rating, and fruit shape rating had similar gains (Wehner and Cramer, 1996a).

Gain was made for fruit yield and shape rating (Wehner and Cramer, 1996a) but not for testcross performance for fruit yield 
and shape rating. One explanation for those cases where there was gain per se, but no gain in testcross performance, is that the population converged on the tester as it was being improved. Gy 14 was used in the development of many cultivars used as parents for these populations (Wehner, 1997, 1998), so the populations have genes in common with the tester. A second explanation is that the populations tested in our study were selected based on fruit yield and shape rating and not for testcross performance for fruit yield and shape rating (Wehner and Cramer, 1996a). In another study, Gy 14 was used successfully as a tester in recurrent selection for hybrid performance (Lertrat and Lower, 1983; 1984).

For the four pickling cucumber populations studied, recurrent selection for improved fruit yield and shape rating resulted in little change in testcross performance for fruit yield and shape rating for most population-season combinations. However, in certain instances gain in testcross performance for fruit yield or shape rating was observed and was positively correlated with a gain in fruit yield or shape rating. In addition, testcross performance for fruit yield and shape rating of most population-cycle-season combinations did not exceed the fruit yield and shape rating of Gy 14 . However, certain high yielding families could be selected from each population-cycle-season combination and used in the development of pickling cucumber cultivars.

\section{Literature Cited}

Cramer, C.S. 1997. Specific combining ability for fruit yield and shape, yield and yield components of cucumber (Cucumis sativus L.) populations improved using recurrent selection. PhD diss. N.C. State Univ., Raleigh.

Cramer, C.S. and T.C. Wehner. 1998a. Performance of three selection cycles from four slicing cucumber populations hybridized with a tester. J. Amer. Soc. Hort. Sci. 123:396-400.

Cramer, C.S. and T.C. Wehner. 1998b. Stand correction methods for cucumber fruit yield. Cucurbit Genet. Coop. Rpt. 21:18-20.

Lertrat, L. and R.L. Lower. 1983. Pickling cucumber population improvement for increased fruit yield. Cucurbit Genet. Coop. Rpt. 6:1819.

Lertrat, L. and R.L. Lower. 1984. Pickling cucumber population im- provement for increased fruit yield II. Cucurbit Genet. Coop. Rpt. 7:9. Nienhuis, J. and R.L. Lower. 1988. Comparison of two recurrent selection procedures for yield in two pickling cucumber populations. J. Amer. Soc. Hort. Sci. 113:272-276.

Schultheis, J.R. 1990. Pickling cucumbers. N.C. State Univ. Agr. Ext. Serv. Hort. Info. Lflt. 14-A.

Smith, O.S., R.L. Lower, and R.H. Moll. 1978. Estimates of heritabilities and variance components in pickling cucumbers. J. Amer. Soc. Hort. Sci. 103:222-225.

Strefeler, M.S. and T.C. Wehner. 1986. Estimates of heritabilities and genetic variances of three yield and five quality traits in three freshmarket cucumber populations. J. Amer. Soc. Hort. Sci. 111:599-605.

Swallow, W.H. and T.C. Wehner. 1986. Optimum plot size determination and its application to cucumber yield trials. Euphytica 35:421-432.

Swallow, W.H. and T.C. Wehner. 1989. Optimum allocation of plots to years, seasons, locations, and replications, and its application to onceover-harvest cucumber trials. Euphytica 43:59-68.

U.S. Dept. Agr. 1998. Agricultural statistics. U.S. Govt. Printing Office, Washington, D.C.

Wehner, T.C. 1982. Weighted selection indices for trials and segregating populations. Cucurbit Genet. Coop. Rpt. 5:18-20.

Wehner, T.C. 1984. Variation for yield within locations in homogenous and heterogeneous cucumber populations. Cucurbit Genet. Coop. Rpt. 7:33-34.

Wehner, T.C. 1989. Breeding for improved yield in cucumber, p. 323359. In: J. Janick (ed.). Plant breeding reviews. vol. 6. AVI Press, Stamford, Conn.

Wehner, T.C. 1997. Three pickling cucumber populations: NCWBP, NCMBP, and NCEP1. HortScience 32:941-944.

Wehner, T.C. 1998. Two special cucumber populations: NCH1 and NCBA1. HortScience 33:766-768.

Wehner, T.C. and C.S. Cramer. 1996a. Gain for pickling cucumber yield and fruit shape using recurrent selection. Crop Sci. 36:1538-1544.

Wehner, T.C. and C.S. Cramer. 1996b. Ten cycles of recurrent selection for fruit yield, earliness and quality in three slicing cucumber populations. J. Amer. Soc. Hort. Sci. 134:322-326.

Wehner, T.C. and C.H. Miller. 1990. Yield of cucumbers in multipleharvest trials with dissimilar genotypes in border rows. HortScience 25:106-108.

Wehner, T.C., T.J. Monaco, and A.R. Bonanno. 1984. Chemical defoliation of cucumber vines for simulation of once-over harvest in small-plot yield trials. HortScience 19:671-673. 